\title{
TRIALS, ERRORS, AND IMPROVEMENTS IN COPRODUCTION OF CLIMATE SERVICES
}

\author{
Erik W. Kolstad, Oda N. Sofienlund, Hanna Kvamsås, Mathew A. Stiller-Reeve, \\ Simon Neby, Øyvind Paasche, Marie Pontoppidan, Stefan P. Sobolowski, Håvard Haarstad, \\ Stina E. Oseland, Lene Omdahl, and Snorre WaAge
}

\begin{abstract}
An honest reflection on experiences in a climate services project is provided, with concrete recommendations on how to put ideas of coproduction into practice.
\end{abstract}

I n September 2005, vast amounts of rain wreaked havoc along the western coast of Norway (Stohl et al. 2008). Major flooding occurred in many locations, and a landslide in Bergen led to the deaths of 3 people ( 10 people were hospitalized and 225 people were evacuated) (Lango 2011). This episode and others have raised the general awareness of the dangers associated with climate change in western Norway. Despite this, and even though it has been known for years that the precipitation in fall and winter is projected to increase in western Norway (Hanssen-Bauer et al. 2003), and that flooding is likely to become more intense (Lawrence and Hisdal
2011), many municipalities have yet to act on their experiences and apply available knowledge.

Realizing that a concerted effort to put climate adaptation on the agenda was required, special advisors at the county administration in Hordaland (the third largest county in Norway) joined with climate researchers to formulate a grant proposal for a pilot project. The main objective was for the researchers to downscale and customize quantitative climate knowledge for practical use in adaptation work for a selection of municipalities in Hordaland. The municipalities' role was to tell the researchers which specific issues they faced and where the need for
AfFiliations: Kolstad AND Stiller-ReEVe-NORCE Climate, Bjerknes Center for Climate Research, and Center for Climate and Energy Transformation, University of Bergen, Bergen, Norway; SOFIENLUND*_Department of Geography, University of Bergen, Bergen, Norway; KvamsÅs - NORCE Society, and Department of Geography, and Center for Climate and Energy Transformation, University of Bergen, Bergen, Norway; NEBY-NORCE Society, and Center for Climate and Energy Transformation, University of Bergen, Bergen, Norway; PAASCHE, PontopPIDAN, AND SOBOLOWSKINORCE Climate, Bjerknes Center for Climate Research, Bergen, Norway; HAARSTAD AND OsELAND-Department of Geography, and Center for Climate and Energy Transformation, University of Bergen, Bergen, Norway; OMdAHL AND WAAGE-Hordaland Fylkeskommune, Bergen, Norway

*CURRENT AFFILIATION: SOFIENLUND-Oslo Kommune, Oslo, Norway

CORRESPONDING AUTHOR: Erik W. Kolstad, erik.kolstad@uib.no

The abstract for this article can be found in this issue, following the table of contents. DOI:10.1175/BAMS-D-18-0201.I

In final form I April 2019

(C)2019 American Meteorological Society

For information regarding reuse of this content and general copyright information, consult the AMS Copyright Policy. 
knowledge was greatest. The proposal was approved and the Hordaklim project was initiated in 2015. We soon ran into challenges.

Many of the challenges in Hordaklim were related to coproduction, or the lack thereof. Coproduction has been defined as "the process through which inputs used to produce a good or service are contributed by individuals who are not 'in' the same organization [as the providers]" (Ostrom 1996), and is related to comanagement (Armitage et al. 2009; Berkes 2009). A growing body of literature suggests that increased interaction through coproduction of knowledge is necessary to address and cope with climate change and to develop and implement adequate adaptation measures (e.g., Lemos and Morehouse 2005; McNie 2013; Porter and Dessai 2017; Wamsler 2017; Lemos et al. 2018). Coproduction has been implemented in many international projects at different levels of society (e.g., Lövbrand 2011; Bremer et al. 2018; Willyard et al. 2018). However, the science-policy interface in western Norway lacked such examples. We knew that coproduction was necessary for responsible climate research and adaptation in our project and that it would not happen just because it is a "good thing" [as pointed out recently by Hickey et al. (2018)]. But, in retrospect, maybe we hoped it would. Materializing this "good thing" was certainly a challenge.

The purpose of this essay is to honestly reflect on our experiences-good and bad-in Hordaklim, and to give a set of concrete recommendations on how to put ideas of coproduction into practice when developing climate services (Brasseur and Gallardo 2016). The authors are climate scientists, social scientists, and special advisors at the county administration, but we mainly use the perspective of climate researchers.

We refer to the public sector employees involved in the project collectively as "practitioners" and the climate and social scientists as "researchers." The main strategy used here is to assess the experiences of the researchers and practitioners, and to contextualize these experiences through joint discussions and revisits of field notes and records from workshops, interviews, group sessions, and project meetings. In other words, this text is based on deliberative introspection rather than on explicit research.

\section{BACKGROUND AND CHRONOLOGY.}

Hordaland has 33 municipalities and has its main seat in Bergen, Norway's second most populous city (population of about 270,000). Located on the western coast, Hordaland has narrow fjords and high mountains (Fig. 1). The driest and wettest meteorological stations in the county are only about $100 \mathrm{~km}$ apart, but the annual precipitation at the latter is more than 4 times as high as at the former $\left(3,537\right.$ vs $\left.840 \mathrm{~mm} \mathrm{yr}^{-1}\right)$. In Norway, local authorities have a pivotal responsibility for climate adaptation and preparedness for weather-related events such

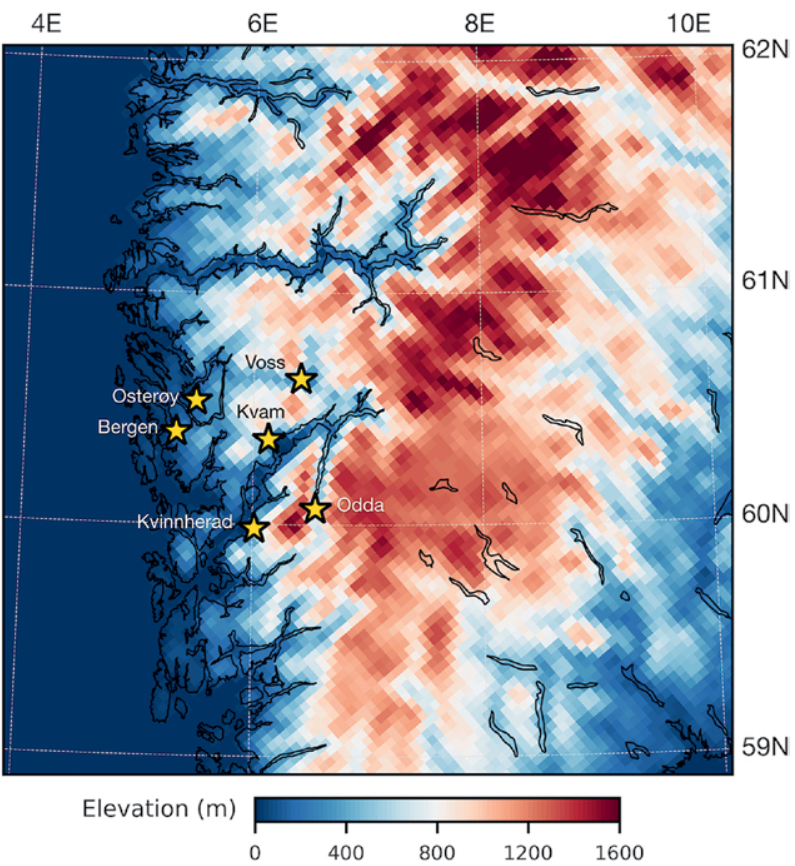

FIG. I. (left) Norway's geographical location in the northeast Atlantic. (right) Magnified image of the black box in the left panel, in which the innermost model domain used for dynamical downscaling in Hordaklim is shown (Pontoppidan et al. 20l8). The grid spacing is $4 \mathrm{~km}$, and the stars denote the six partner municipalities. 
as flooding and landslides. The climate projections that were available before 2014, when the Hordaklim proposal was being developed, were based on models with too-coarse resolutions to represent the diverse geography in western Norway. Discussions between the county administration of Hordaland and climate researchers highlighted a need for new, downscaled projections (Pontoppidan et al. 2018).

The proposal specified that the main objective of Hordaklim was to provide downscaled climate data and to tailor these to municipalities in Hordaland to make it easier for them to adapt to climate change. This included communication with the users to map their needs for information about future regional changes in weather and climate variables, and subsequently dissemination of the climate projections to the end users. A substantive plan for executing this dialogue was laid out, with six proposed meetings between the users (i.e., the municipalities, the county, and the general population) and the researchers each year. Most of the proposed work related to finding the best possible regional model setup and then producing new downscaled climate projections (the model development part is not the main focus of this paper). More than $50 \%$ of the budget was allocated to "production of downscaled climate data."

After the project was initiated, it quickly became clear that the efforts required for coproducing the climate information had been severely underestimated. To add to this, the modeling efforts were hampered by technical problems and a gradual realization that the proposed methodologies were not as mature as was thought when the proposal was written. As a consequence, the new projections were not ready until a few months after the end of the project. Still, the pilot project was considered a success by the county and the researchers. Perhaps the most important outcome was the highlighting of the challenges that are the subject of this paper. The experiences along the way led to a gradual transformation into a truly interdisciplinary project in which natural scientists, social scientists, and county and municipal practitioners worked together in new ways. These new collaborations across disciplines and institutions have been important factors for securing funding for several new research projects, with a total budget of several million U.S. dollars (see Fig. 2 for an example). In addition, Hordaland County has now allocated a 70\% position to climate adaptation facilitation starting in 2018. The two people currently sharing this position (Omdahl and Waage) organized a seminar for the Hordaklim municipalities and the researchers involved in the project in May 2018, ensuring that the work that was started in Hordaklim will be continued.

While there were many positive outcomes of Hordaklim, we now substantiate the central challenges that we encountered, narrowed down to four areas we found to be particularly relevant: allocation of resources, addressing the usability gap, building trust across disciplines and sectors, and the importance of continuity.

MAIN CHALLENGES IN HORDAKLIM. Allocating sufficient resources to coproduction. There is ample evidence suggesting that coproduction takes time and effort (Dilling and Lemos 2011). Through an interactive and iterative approach, trust and collaboration between the coproducers may enhance the perception of the value, credibility, and legitimacy of the knowledge (Healy 1999; Cash et al. 2003; Lemos et al. 2012; Bremer and Meisch 2017). In some respects, the Hordaklim proposal clearly conveyed that coproduction and dialogue were essential, but out of the eight tasks that were defined, only two 
had to do with coproduction. The first task was to facilitate the meetings between the researchers and municipal practitioners, and the last task was to tailor the downscaled projections (the remaining six tasks were all related to the modeling). But only about $10 \%$ of the budget was allocated to the first task (dialogue) and this did not include any salary costs. According to the proposal, the county administration's main task was to facilitate the meetings, but it was not explicitly stated how much time and resources the municipalities were expected to spend. In hindsight, this vagueness was clearly a mistake. The project proposal was largely influenced by the researchers' views, and the municipalities were not sufficiently consulted in the early phase. As stated by one of the municipal practitioners, "A solution was presented before one actually knew what was needed" (Sofienlund 2018).

As it happened, the county administration did not organize the intended six thematic group meetings per year. We believe that one of the main reasons for this was that the budget did not include salary costs for attending the group meetings. Knowing that municipal practitioners need to invest a considerable amount of time and resources in coproduction projects, and that many Norwegian municipalities experience a lack of resources, the project group (who were for a large part not involved in writing the proposal) felt that it would have been unreasonable to ask the practitioners to invest that much time in the project. One of the most important lessons learned in Hordaklim was that the good intentions of doing coproduction should have been buttressed by a realistic budget that invested in practitioner participation.

Another key challenge that came to light quickly was that the initial Hordaklim project group did not include any "skilled group facilitators" (Hewitt et al. 2017). The first interaction between the researchers and the municipal practitioners took place early in 2015, when the principal investigator (PI) visited the four original partner municipalities to start mapping their needs for climate information. The visits started with a general presentation of the project, followed by unstructured conversations. These interactions gave a wealth of relevant information, but the PI quickly perceived that performing such interviews and meetings was beyond his area of expertise. There was a need for an experienced person to take notes, both to prevent the information from being forgotten and to organize the information in a structured manner. Erroneously assuming that social scientists are coproduction experts by default (and that coproduction experts had to be social scientists by training), the
PI recruited a small group of social scientists to help with these tasks. As it turned out, these suffered the same shortcomings as the natural scientists: they were scientists with particular research interests, and not coproduction experts. Thus, it took time for them to realize what was needed, as they started out seeing climate adaptation and climate services as interesting fields of social science inquiries rather than taking an active role in the coproduction.

Following the individual site visits by the PI, we thought it would be useful to gather all the practitioners in one place, in order to get to know each other and to identify common needs for climate information. We therefore organized two-day workshops in the autumn of 2015 and the spring of 2016. These were useful in that it became clear that flooding due to increased rainfall was high on the agenda in all the municipalities. With the limited resources available for modeling at that stage in the project, the project group decided to focus the modeling on intense precipitation. The workshops also provided a forum for promoting climate literacy (by informing the municipalities about how and why the high-resolution modeling was required), and more generally for the practitioners to exchange experiences with colleagues who were "in the same boat." But too many of the participants at the workshops were "passive onlookers" (Steinert 1992) and did not get an opportunity to share their experiences and needs with the researchers. This problem could obviously have been mitigated by employing more skilled facilitators. The need for one-to-one dialogue between the researchers and the practitioners was also evident.

To meet the practitioners on their home turf, where we hoped that it would be easier for them to communicate their needs for climate information, a group consisting of climate scientists, social scientists, and county personnel representing both the planning and climate sectors visited each of the six municipalities in turn during the first half of 2017 (see Fig. 3). These meetings were perceived by the project group to be instrumental for understanding the complexity of climate adaptation at the municipal level. At the workshops in the earlier phase of the project, there was normally only one or two representatives from each municipality. Now, the project group was able to meet with more representatives from each municipality, representing a wider spectrum of expertise. As a result, we learned more about the responsibilities and tasks conducted by the practitioners. Through a two-way dialogue, we developed a more common understanding of the local challenges associated with climate change adaptation. Furthermore, these local 
meetings made possible a more interactive form of communication between the climate scientists and the practitioners, and questions could be asked as soon as anything became unclear. This was not the case during larger meetings where the audience often consisted of 30-40 people. As such, these meetings represented a breakthrough for bridging the gap between research and local adaptation work.

Another key outcome of the site visits was that the county advisors realized that it was important that they took a more active role

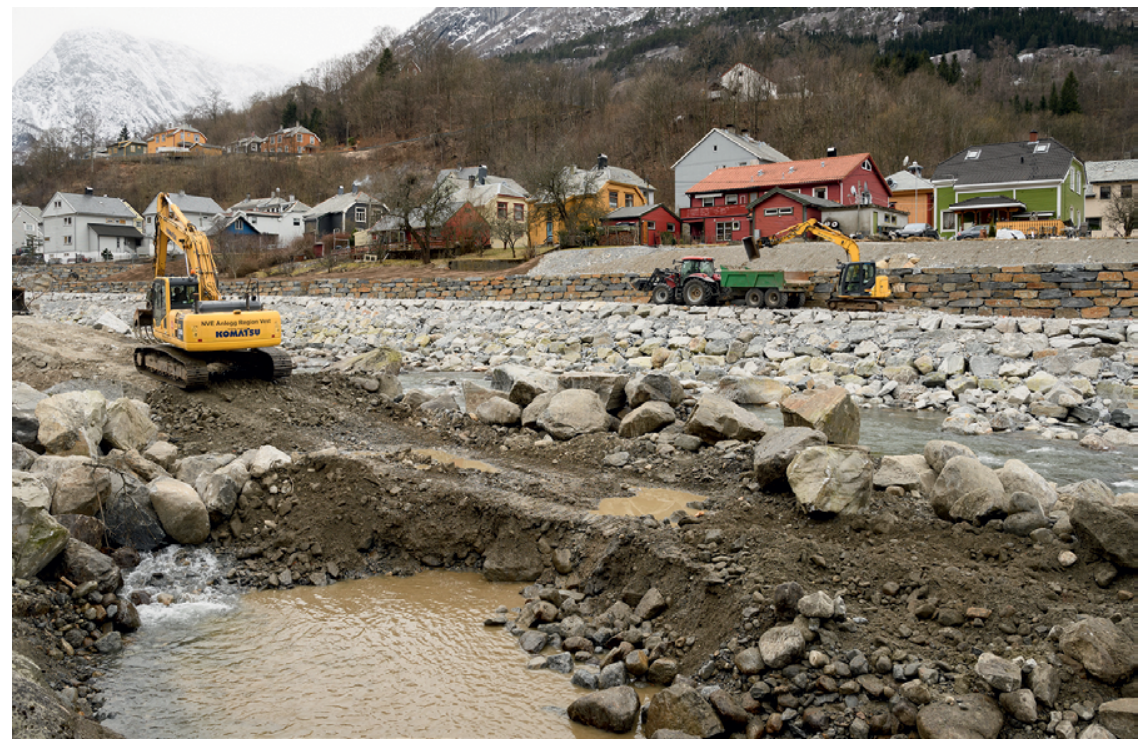

Fig. 3. During a visit to Odda in Mar 2017, some of the Hordaklim researchers got to see the extensive repairs being done to the River Opo after the flooding episode in Oct 2014 (Pontoppidan et al. 2017). Photo by Erik Kolstad. in the project. In fact, one of the most important experiences of the researchers was the need for boundary organizations (e.g., Lemos et al. 2014; Buizer et al. 2016), which "exist at the frontier of... politics and science," and "involve participation of actors from both sides of the boundary, as well as professionals who serve a mediating role" (Guston 2001). How these actors interact and collaborate across the boundary in order to link knowledge to action is known as "boundary work" and can take many forms (van Kerkhoff and Lebel 2006; Clark et al. 2016). In Norway, the regional county politicaladministrative level, situated between the municipalities and the central government, might be ideal for such boundary work (Dannevig and Aall 2015).

Bridging the usability gap. Even though climate-related disasters had struck several of the municipalities in recent years, and further calamities were projected to occur due to future climate change, it turned out that it was difficult for many practitioners to identify explicit questions that could be readily resolved by the climate scientists. There was an obvious usability gap (Lemos et al. 2012; Briley et al. 2015; Hanssen et al. 2015) that we needed to narrow. Specifically, we had expected the practitioners to be more familiar with the projections of climate impacts and how these would influence their municipalities. This meant that the coproduction process had to start at a more basic level than what we had come to expect after reading the literature (e.g., Lemos and Morehouse 2005; Porter and Dessai 2017).

An anecdote from the early phase of Hordaklim illustrates how the usability gap was wider than anticipated. While traveling to the municipalities in 2015, the PI had conversations with employees from different departments. One of these employees worked mainly with forestry. Initially, this person was reluctant to set aside time for a conversation, as they did not think that climate change would have a large impact on forests. However, during the conversation, several climate change impacts on forests were identified, such as 1) changes in the frequency of storms, which might lead to decreases or increases in windthrow events; 2) changes in temperatures that could influence which tree types one should plant; and 3) milder winters, which might lead to less dry snow but more wet snow, a major driver of tree damage. As a result, suggestions for several climate indices were broached, such as a complex index that includes temperature, precipitation, and wind.

The dialogue between the PI and the forestry practitioner strongly influenced how the PI thought about presenting the data. The former had a clear sense that his data would be useful, whereas the latter did not. There was a mismatch between the supply and demand of climate knowledge (Sarewitz and Pielke 2007; McNie 2007). The main takeaway message from this example is that it is often more fruitful to start a conversation or interview by asking what a person's responsibilities and everyday experiences are, rather than asking "What kind of information do you need?" 
The diverging expectations of information transfer in Hordaklim are also highly relevant when discussing the usability gap. In the grant proposal, the word "dialogue" was used several times, including in this context: "Through dialogue between the users (municipalities) and the providers (researchers) the specific knowledge will become applicable." The nouns used in the quotation above ("users" and "providers") alluded to a more traditional and unidirectional provider-to-user model. The secondary objectives mentioned in the previous sections also contained the terms "users" and "end users." This is not merely a semantic issue. Interviews with participants revealed that they perceived the project differently to the researchers, as the framing and wording of the project was based on the provider-to-user model, even though the goal was coproduction (Sofienlund 2018). The use of the terms "provider" and "user" influenced how the municipal practitioners chose to participate and how they understood their responsibilities. Through the project, and especially in the beginning, many municipal workers expected a concrete data delivery from the climate scientists (the providers), while the providers expected the user group to participate more actively to identify and communicate their needs. Using such terminology already in the proposal stage diminishes the feeling that everyone is an equal partner in a coproduction project (Willyard et al. 2018).

Getting to know each other's realities. Initially, the climate scientists in Hordaklim did not know much about the landscape in which municipal practitioners operate or their daily realities of time pressures, economic limitations, and navigating complicated regulations. Academics and practitioners typically relate to knowledge in different ways due to their diverging backgrounds, work requirements, and time frames. In academia, research is about development of knowledge, the goal is to reach for "the best," and uncertainty can be seen as a call for more research. But this may be perceived by practitioners as a reluctance to share knowledge. During the second Hordaklim workshop, the PI suggested to postpone the data delivery because it would be possible to get more accurate data later on through one of the spin-off projects, which had more resources for the model development. This was not well received by the practitioners. Several of them expressed in interviews that they needed a concrete delivery to justify the time that they had spent on the project (Sofienlund 2018). This example points to a discrepancy between scientists' push for the "best" product and the more pragmatic need for a product that is "good enough."

Another insight gained from Hordaklim is that it can be important for the practitioners to get access to knowledge when they actually work on specific plans or measures where that knowledge is applicable. For example, one of the municipalities (Voss) was initially reluctant to participate in Hordaklim, as their knowledge needs were urgent and the data would be presented too late to be used directly for the flood protection measures they would have to take during the project period. However, after years of two-way dialogue - which we assume has built trust-Voss is now an active partner in Hordaflom, which is a new project with a specific focus on flooding. We believe that this is because they realize that the challenges associated with climate change (and their need for information) are not going away.

In many cases, climate information must also be issued by the correct authority. A typical example is that maps of 200-yr-flood return levels are produced by the Norwegian Water Resources and Energy Directorate (NVE). These lines on the map are the most important constraints for construction of buildings, roads, and other infrastructure. In 2011, Voss inaugurated a large new building with a library, a cinema, and other cultural facilities. Its foundation had been built $30 \mathrm{~cm}$ above the 200 -yr-flood return level at the time. In 2014, an intense rainfall event (Pontoppidan et al. 2017) led to flooding that caused extensive damage. The return level has now been moved higher than the foundations of the building. While recommendations from governmental agencies are important constraints for construction and development, they often lack functional detail for local-level application. In fact, this was one of the main motivations for the Hordaklim project. Municipalities are allowed to use new and locally relevant information, but what if these are in conflict with the recommendations from the agencies? Who decides what information can be used?

There was clearly a need to expand the dialogue to include not only researchers and practitioners, but also employees at government agencies, insurance companies, and consultancies, as well as politicians. We therefore organized the successful hackathon-like (Pogačar and Žižek 2016) Klimathon2018 seminar early in 2018, near the end of the Hordaklim project period. Over a period of two days, 12 interdisciplinary and intersectoral groups collaborated to design practical and strategic solutions to the challenges of planning and implementing climate adaptation at the local level. A second Klimathon was held in March 
2019 , and plans are underway for this to become an annual event. As this ensures sustainability and continuity of the coproduction between sectors and across disciplines, the Klimathon seminars are one of the most valuable legacies of Hordaklim.

Keep calm and carry on. In Hordaklim, we found that our roles as scientists underwent a continual transformation. We started the work with a somewhat dated and naïve preconception that there would be a clearly stated need for our data, compelling us to solely focus on producing those data using climate models. However, it was often as important to be able to communicate with the decision-makers as to perform impartial desktop research. The balance between these two roles can be hard to strike. The time spent on coproduction reduces time spent on other activities, some of which are critical for a scientist's career (e.g., writing papers).

Continuity, or rather lack thereof, was an important factor in Hordaklim. For instance, a total of four persons acted as project coordinator throughout the project's lifetime. This weakened the county's ability to act as the link between the researchers and the municipalities. Climate adaptation work at the local level is often driven by individuals, or "champions" (Dannevig et al. 2013; Meijerink and Stiller 2013). Some municipalities simply do not have the resources and staffing to follow up these tasks (Westskog et al. 2017). This can often also be said of research institutions, where the pool of researchers that are willing and able to work on coproduction may be limited (Wamsler 2017). It is also a potential problem that the traditional project framework with specified start and end dates is not designed to foster continuity in cross-institutional work. Key personnel will often be forced to move on to new projects when the funding period ends.

The key person-dependency problem was one of our main internal discussion topics. It gradually became clear to us that it was crucial that there was a degree of continuity in the space between the scientists and the municipalities, which in our case was occupied by the county personnel. As mentioned, it took years for Voss to acknowledge the value of being part of Hordaklim and its related projects. Learning from the regrettable lack of continuity in the project, we strongly recommended that this "blank space" should be claimed. The responsibilities associated with this space could be to foster boundary work by acting as a mediator, liaison, or facilitator between the researchers and the practitioners (Dilling and Lemos 2011; Kirchhoff et al. 2013; Dannevig and Aall 2015; Hanssen et al. 2015).

\section{CONCLUSIONS AND RECOMMENDA-}

TIONS. The Hordaklim climate service pilot project was initially framed as a coproduction project, with an ambitious plan for dialogue between the climate researchers and the municipal practitioners. However, the budget allocated most of the resources to model development, with scarce funding for executing the all-important dialogue. In addition, there was a clear lack of competence in dialogue facilitation in the project group. These shortcomings taught us the hard way that coproduction is required in all phases of a research process-from framing research problems and generating questions, to interpreting results and assessing their validity and utility, to attempting to meaningfully integrate science with on-the-ground local knowledge and practices. Our overarching finding was that the time and effort required to achieve coproduction must be reflected in the allocation of resources for climate service projects.

We also learned that there was a wide gap between what the climate researchers anticipated that the municipalities needed and what they did in fact require. In part, this was caused by the climate scientists' ignorance about the workings of local government and the "command lines" in climate adaptation work. Looking back, it is clear that we did not know who was responsible for gathering climate information, how this information would be used in planning adaptive measures, who would decide which measures to implement, and crucially, in what form and from which institution this information must be disseminated for it to be actionable (e.g., Kirchhoff et al. 2013; McNie et al. 2016). We found that sustained dialogue and meeting the municipalities on their "home turf" were helpful in bridging the "usability gap."

Maintaining a certain continuity in the collaboration is important. Even when one understands the concept of coproduction and has a good overview of the literature on the subject, successful coproduction requires time, effort, and a willingness to change. There is a need to "share power and responsibility" (Hickey et al. 2018), and that takes time. In the case of time-limited research projects, ideally the same people should be involved from the preproposal stage until the project ends. And well before that, the experiences made during the project should be utilized to formulate new collaborations involving many of the same people. Otherwise, some of the substantial investments to achieve coproduction would be squandered.

Based on our experiences, we now present some recommendations. We believe these are relevant not just for climate services, but for many other 
contexts in which multiple disciplines, sets of expertise, and organizations/institutions are involved as stakeholders. ${ }^{1}$

1) Avoid dividing the participants into predetermined groups based on their traditional responsibilities. This can have the undesired effect that the participants fall into their usual roles. Tip: Do not refer to the traditional end users (i.e., stakeholders and decision-makers) as "users," but rather as, for example, "partners," "practitioners," or "coproducers." Similarly, do not refer to the climate scientists as "providers."

2) When allocating resources, make sure to set aside sufficient funding for coproduction, including salary, travel, and other costs associated with organizing site visits and workshops. Tip: Recruit personnel with experience in facilitating group meetings and performing interviews with practitioners, but be aware of the differences between facilitating coproduction on the one hand and working with qualitative methods on the other.

3) Involve as many of the coproducers as possible already in the preproposal stage, and allow ample time for dialogue. This is important to avoid a feeling of being presented with a solution to a problem that may not exist. Tip: Rather than asking the practitioners what kind of information they need, initiate a dialogue about their responsibilities and how these relate to climate change. And visit practitioners where they work. This shows commitment and will often make people more relaxed.

4) Clarify expectations and responsibilities to prevent misunderstandings and frustration and ensure that the involved actors know their responsibilities and what is expected from them. Tip: Avoid the term "delivery," as this can promote apathy if the practitioners think of themselves as passive recipients.

5) Make the gap between climate scientists and municipalities as narrow as possible. Tip: Make use of boundary organizations and/or develop regional hubs that can facilitate coproduction and offer municipalities climate adaptation guidance.

ACKNOWLEDGMENTS. The authors thank the editorial team and three anonymous reviewers for contributing to an improved text. The work was supported by project funding from the Research Council of Norway: R3 (Grant 255397); and from the Regional Research Fund of western

${ }^{1}$ We thank one of the reviewers for making this point.
Norway: Hordaklim (Grant 245403), Hordaflom (Grant 269682), and Hordaplan (Grant 260037).

\section{REFERENCES}

Armitage, D. R., and Coauthors, 2009: Adaptive co-management for social-ecological complexity. Front. Ecol. Environ., 7, 95-102, https://doi .org/10.1890/070089.

Berkes, F., 2009: Evolution of co-management: Role of knowledge generation, bridging organizations and social learning. J. Environ. Manage., 90, 1692-1702, https://doi.org/10.1016/j.jenvman.2008.12.001.

Brasseur, G. P., and L. Gallardo, 2016: Climate services: Lessons learned and future prospects. Earth's Future, 4, 79-89, https://doi.org/10.1002/2015EF000338.

Bremer, S., and S. Meisch, 2017: Co-production in climate change research: Reviewing different perspectives. Wiley Interdiscip. Rev.: Climate Change, 8, e482, https://doi.org/10.1002/wcc.482.

-, M. Stiller-Reeve, A. Blanchard, N. Mamnun, Z. Naznin, and M. Kaiser, 2018: Co-producing "postnormal" climate knowledge with communities in northeast Bangladesh. Wea. Climate Soc., 10, 259-268, https://doi.org/10.1175/WCAS-D-17-0033.1.

Briley, L., D. Brown, and S. E. Kalafatis, 2015: Overcoming barriers during the co-production of climate information for decision-making. Climate Risk Manage., 9, 41-49, https://doi.org/10.1016/j .crm.2015.04.004.

Buizer, J., K. Jacobs, and D. Cash, 2016: Making shortterm climate forecasts useful: Linking science and action. Proc. Natl. Acad. Sci. USA, 113, 4597-4602, https://doi.org/10.1073/pnas.0900518107.

Cash, D. W., W. C. Clark, F. Alcock, N. M. Dickson, N. Eckley, D. H. Guston, J. Jäger, and R. B. Mitchell, 2003: Knowledge systems for sustainable development. Proc. Natl. Acad. Sci. USA, 100, 8086-8091, https://doi.org/10.1073/pnas.1231332100.

Clark, W. C., T. P. Tomich, M. Van Noordwijk, D. Guston, D. Catacutan, N. M. Dickson, and E. McNie, 2016: Boundary work for sustainable development: Natural resource management at the Consultative Group on International Agricultural Research (CGIAR). Proc. Natl. Acad. Sci., 113, 4615-4622, https://doi.org/10.1073/pnas.0900231108.

Dannevig, H., and C. Aall, 2015: The regional level as boundary organization? An analysis of climate change adaptation governance in Norway. Environ. Sci. Policy, 54, 168-175, https://doi.org/10.1016/j .envsci.2015.07.001.

—, G. K. Hovelsrud, and I. A. Husabø, 2013: Driving the agenda for climate change adaptation in 
Norwegian municipalities. Environ. Plann., 31C, 490-505, https://doi.org/10.1068/c1152.

Dilling, L., and M. C. Lemos, 2011: Creating usable science: Opportunities and constraints for climate knowledge use and their implications for science policy. Global Environ. Change, 21, 680-689, https:// doi.org/10.1016/j.gloenvcha.2010.11.006.

Guston, D. H., 2001: Boundary organizations in environmental policy and science: An introduction. Sci. Technol. Hum. Values, 26, 399-408, https://doi .org/10.1177/016224390102600401.

Hanssen, G. S., H. Hofstad, and H. Hisdal, 2015: Manglende lokal tilpasning til klimaendringer: Kan flernivånettverk øke tilpasningskapasiteten (Lack of local climate change adaptation: Can multilevel networks increase adaptive capacity?)? Kart Plan, 75, 64-78.

Hanssen-Bauer, I., E. J. Førland, J. Haugen, and O. Tveito, 2003: Temperature and precipitation scenarios for Norway: Comparison of results from dynamical and empirical downscaling. Climate Res., 25, 15-27, https://doi.org/10.3354/cr025015.

Healy, S., 1999: Extended peer communities and the ascendance of post-normal politics. Futures, 31, 655669, https://doi.org/10.1016/S0016-3287(99)00025-7.

Hewitt, C. D., R. C. Stone, and A. B. Tait, 2017: Improving the use of climate information in decisionmaking. Nat. Climate Change, 7, 614-616, https://doi .org/10.1038/nclimate3378.

Hickey, G., T. Richards, and J. Sheehy, 2018: Coproduction from proposal to paper. Nature, 562, 29-31, https://doi.org/10.1038/d41586-018-06861-9.

Kirchhoff, C. J., M. C. Lemos, and S. Dessai, 2013: Actionable knowledge for environmental decision making: Broadening the usability of climate science. Annu. Rev. Environ. Resour., 38, 393-414, https://doi .org/10.1146/annurev-environ-02 112-11 828.

Lango, P., 2011: Hatlestad-raset (The Hatlestad landslide). Organisering, Samfunnssikkerhet og Krisehåndtering, A. L. Fimreite et al., Eds., Universitetsforlaget, 216-234.

Lawrence, D., and H. Hisdal, 2011: Hydrological projections for floods in Norway under a future climate. NVE Tech. Rep., 54 pp.

Lemos, M. C., and B. J. Morehouse, 2005: The co-production of science and policy in integrated climate assessments. Global Environ. Change, 15, 57-68, https://doi.org/10.1016/j.gloenvcha.2004.09.004.

—, C. J. Kirchhoff, and V. Ramprasad, 2012: Narrowing the climate information usability gap. Nat. Climate Change, 2, 789-794, https://doi .org/10.1038/nclimate1614.

,-- , S. E. Kalafatis, D. Scavia, and R. B. Rood, 2014: Moving climate information off the shelf:
Boundary chains and the role of RISAs as adaptive organizations. Wea. Climate Soc., 6, 273-285, https:// doi.org/10.1175/WCAS-D-13-00044.1.

— - and Coauthors, 2018: To co-produce or not to coproduce. Nat. Sustainability, 1, 722-724, https://doi .org/10.1038/s41893-018-0191-0.

Lövbrand, E., 2011: Co-producing European climate science and policy: A cautionary note on the making of useful knowledge. Sci. Public Policy, 38, 225-236, https://doi.org/10.3152/030234211X12924093660516.

McNie, E. C., 2007: Reconciling the supply of scientific information with user demands: An analysis of the problem and review of the literature. Environ. Sci. Policy, 10, 17-38, https://doi.org/10.1016/j.envsci .2006.10.004.

_ 2013 : Delivering climate services: Organizational strategies and approaches for producing useful climate-science information. Wea. Climate Soc., 5, 14-26, https://doi.org/10.1175/WCAS-D-11 -00034.1 .

— - A. Parris, and D. Sarewitz, 2016: Improving the public value of science: A typology to inform discussion, design and implementation of research. Res. Policy, 45, 884-895, https://doi.org/10.1016/j .respol.2016.01.004.

Meijerink, S., and S. Stiller, 2013: What kind of leadership do we need for climate adaptation? A framework for analyzing leadership objectives, functions, and tasks in climate change adaptation. Environ. Plann., 31C, 240-256, https://doi.org/10.1068 /c11129.

Ostrom, E., 1996: Crossing the great divide: Coproduction, synergy, and development. World Dev., 24, 1073-1087, https://doi.org/10.1016/0305 -750X(96)00023-X.

Pogačar, K., and A. Žižek, 2016: Urban hackathonAlternative information based and participatory approach to urban development. Procedia Eng., 161, 1971-1976, https://doi.org/10.1016/j .proeng.2016.08.788.

Pontoppidan, M., J. Reuder, S. Mayer, and E. W. Kolstad, 2017: Downscaling an intense precipitation event in complex terrain: The importance of high grid resolution. Tellus, 69A, 1271561, https://doi.org/10 $.1080 / 16000870.2016 .1271561$.

—, E. W. Kolstad, S. P. Sobolowski, and M. P. King, 2018: Improving the reliability and added value of dynamical downscaling via correction of large-scale errors: A Norwegian perspective. J. Geophys. Res. Atmos., 123, 11 875-11 888, https://doi .org/10.1029/2018JD028372.

Porter, J. J., and S. Dessai, 2017: Mini-me: Why do climate scientists misunderstand users and their needs? 
Environ. Sci. Policy, 77, 9-14, https://doi.org/10.1016/j .envsci.2017.07.004.

Sarewitz, D., and R. A. Pielke Jr, 2007: The neglected heart of science policy: Reconciling supply of and demand for science. Environ. Sci. Policy, 10, 5-16, https://doi.org/10.1016/j.envsci.2006.10.001.

Sofienlund, O. N., 2018: Det beste er det godes fiende (The best is the enemy of the good). Master's thesis, Dept. of Geography, University of Bergen, 143 pp.

Steinert, Y., 1992: Twelve tips for conducting effective workshops. Med. Teach., 14, 127-131, https://doi .org/10.3109/01421599209079478.

Stohl, A., C. Forster, and H. Sodemann, 2008: Remote sources of water vapor forming precipitation on the Norwegian west coast at $60^{\circ} \mathrm{N}-\mathrm{A}$ tale of hurricanes and an atmospheric river. $J$. Geophys. Res., 113, D05102, https://doi.org/10.1029 /2007JD009006. van Kerkhoff, L., and L. Lebel, 2006: Linking knowledge and action for sustainable development. Annu. Rev. Environ. Resour., 31, 445-477, https://doi .org/10.1146/annurev.energy.31.102405.170850.

Wamsler, C., 2017: Stakeholder involvement in strategic adaptation planning: Transdisciplinarity and co-production at stake? Environ. Sci. Policy, 75, 148-157, https://doi.org/10.1016/j.envsci.2017.03 .016 .

Westskog, H., G. K. Hovelsrud, and G. Sundqvist, 2017: How to make local context matter in national advice: Towards adaptive comanagement in Norwegian climate adaptation. Wea. Climate Soc., 9, 267-283, https://doi.org/10.1175/WCAS-D-16-0063.1.

Willyard, C., M. Scudellari, and L. Nordling, 2018: How three research groups are tearing down the ivory tower. Nature, 562, 24-28, https://doi.org/10.1038 /d41586-018-06858-4.

\section{FROM AMS BOOKS}

\section{"A thoughtful analysis of actions that we need to take to reduce the impacts of extreme weather... a must-read for everyone with an interest in the weather and climate." \\ - FRANKLIN W. NUTTER, \\ President, Reinsurance Association of America}

\section{Living on the Real World: How Thinking and Acting Like Meteorologists Will Help Save the Planet WILLIAM H. HOOKE}

Meteorologists sift through a deluge of information to make predictions every day. Instead of being overwhelmed by the data and possibilities, they focus on small bits of information while using frequent collaboration to make decisions. With climate change a reality, William H. Hooke suggests we look to the way meteorologists operate as a model for how we can solve the twenty-first century's most urgent environmental problems. 